\title{
Advanced Oxidation Protein Products Induce Inflammatory Response in Fibroblast-Like Synoviocytes through NADPH Oxidase -Dependent Activation of NF-KB
}

\author{
Shuai Zhenga,c Zhao-Ming Zhonga,c Shuai Qin ${ }^{\mathrm{b}}$ Guo-Xian Chen ${ }^{\mathrm{a}}$ Qian Wu \\ Ji-Huan Zeng ${ }^{a}$ Wen-Bin Yea Wei Li ${ }^{a}$ Kai Yuan ${ }^{a}$ Ling Yao ${ }^{a}$ Jian-Ting Chen ${ }^{a}$ \\ aDepartment of Orthopedic Spinal Surgery, Nanfang Hospital, Southern Medical University, \\ Guangzhou, 'Department of Ophthalmology, The People's Hospital of Zhuhai, Zhuhai, China; 'Author's \\ contributions: Shuai Zheng and Zhao-Ming Zhong contributed equally to this work
}

\section{Key Words}

Advanced oxidation protein products • Fibroblast-like synoviocytes $\bullet$ Inflammatory response $\bullet$ Reactive oxygen species • Oxidative Stress

\begin{abstract}
Background: Advanced oxidation protein products (AOPPs), a marker of oxidative stress, are prevalent in many kinds of disorders. Rheumatoid arthritis (RA), mainly resulting from the dysfunction of fibroblast-like synoviocytes (FLSs), is related to oxidative stress. Although the increased levels of AOPPs in RA patients were reported, the effect of AOPPs on FLSs function still remains unclear. Therefore, our study aims to investigate whether AOPPs have an effect on the inflammatory response of FLSs in vitro. Methods: FLSs obtained from both knees of rats were treated with or without AOPPs-modified rat serum albumin (AOPPs-RSA) in vitro. The mRNA and protein expression of tumor necrosis factor (TNF)- $\alpha$, interleukin(IL)-1 $\beta$, matrix metalloproteinases(MMP)-3, MMP-13 and vascular endothelial growth factor (VEGF) were measured by real-time quantitative polymerase chain reaction and enzyme-linked immunosorbent assay (ELISA), respectively. Reactive oxygen species (ROS) generation was detected by fluorescent microscope and fluorescence microplate reader. Immunoprecipitation, Co-Immunoprecipitation and western blot were performed to examine the activity of nicotinamide adenine dinucleotide phosphate (NADPH) oxidase and nuclear factor kappa $B$ (NF-KB). Results: Exposure of FLSs to AOPPs upregulated the mRNA and protein expression of TNF- $\alpha$, IL-1 $\beta$, MMP-3, MMP-13 and VEGF in a concentration dependent manner. AOPPs treatment triggered ROS production in FLSs, which was significantly abolished by ROS
\end{abstract}


scavenger $\mathrm{N}$-acetyl-L-cysteine (NAC), superoxide dismutase (SOD), NADPH oxidase inhibitors diphenyleneiodonium (DPI) and apocynin. Challenged AOPPs induced phosphorylation of $\mathrm{p} 47^{\text {phox }}$, triggered an interaction between $\mathrm{p} 47^{\text {phox }}, \mathrm{p} 22^{\text {phox }}$ and $\mathrm{gp} 91^{\text {phox }}$, and significantly upregulated expression of NADPH oxidase subunits $p 47^{\text {phox }}, \mathrm{p} 22^{\text {phox }}$ and gp91 phox. IKB degradation and nuclear translocation of NF-KB p65 induced by AOPPs were significantly blocked by SOD, NAC, DPI and apocynin. Conclusions: These data indicate that AOPPs induce inflammatory response in FLSs is medicated through NADPH oxidase-dependent activation of NF-KB.

Copyright (C) 2013 S. Karger AG, Basel

\section{Introduction}

Advanced oxidation protein products (AOPPs), considered as a novel marker of oxidantmediated protein damage, are dityrosine-containing and cross-linking protein products mainly formed during oxidative stress by reaction of plasma albumin with chlorinated oxidants $[1,2]$.

AOPPs were firstly found in the plasma of patients undergoing dialysis [2] and were subsequently found in subjects with diabetes [3]. In addition, higher levels of AOPPs have also been found in patients with metabolic syndrome [4], chronic inflammatory bowel diseases [5], and obesity [6], which may suggest the accumulation of AOPPs could be related to some pathophysiologic conditions.

Oxidative stress, a pathological condition begins by excessively generating reactive oxygen species (ROS), as a result of the imbalance between peroxidation and antioxidant defense systems. The plasma concentration of AOPPs is closely correlated with the level of dityrosine, a hallmark of oxidized protein, and pentosidine, a marker of protein glycoxidation which is related to oxidative stress [7]. Oxidative damage to proteins is reflected by increased levels of AOPPs. Therefore, AOPPs had been widely considered as oxidative stress markers [1].

Also apart from being regarded as oxidative stress makers, AOPPs has also been shown to be an effector molecule taking part in many biological events. There have been reported that AOPPs can induce vascular endothelial dysfunction and accelerated atherosclerosis by elevating the level of oxidative stress and over-expression of inflammatory factor $[8,9]$. AOPPs have also shown to trigger respiratory burst and inflammation through the activation of immune cells such as monocyte [1]. Furthermore, we have earlier demonstrated that AOPPs can inhibit proliferation and differentiation of rat osteoblast-like cells through ROSdependent NF- $\kappa B$ pathway [10].

Rheumatoid arthritis (RA) is a chronic inflammatory and autoimmune disease, characterized by synovial proliferation and destruction of articular cartilage at multiple joints [11]. Though the exact mechanism of the disease is not clearly understood, the fibroblast-like synoviocytes (FLSs), which secrete synovial fluid and prodce cytokines, are thought to play an important role involving the joint destruction [12].

It is well known that tumor necrosis factor (TNF) and interleukin (IL)-1 are mediators of the cellular response, enhance inflammation and destruction in various ways, mostly through effects on FLSs [13]. The over-expression of the proinflammatory cytokines such as TNF- $\alpha$, IL-1 $\beta$ and proangiogenic factor, such as vascular endothelial growth factor (VEGF) in FLSs suggestes that FLSs are involved in regulating inflammation and angiogenesis [14].

Matrix metalloproteinases (MMPs) are zinc- and calcium-dependent proteases that contribute to tissue remodelling during development, morphogenesis, inflammation and so on. The synovial tissue destruction observed in RA is due to the activation MMPs mainly secreted by FLSs, macrophages and chondrocytes [15]. Increased levels of MMPs in the synovial fluid of patients with RA are capable of virtually degrading all structural proteins present at the joints [16]. Therefore, the elevated levels of MMPs in synovial fluid mainly secreted by FLSs may be the main cause of synovium and cartilage erosion. 
There have been increasing evidence to support that oxidative stress plays a critical role in RA $[17,18]$. Several factors are involved in the development of oxidative stress in the joints of RA patients, including increased pressure in the synovial cavity, reduced capillary density, vascular changes and an increased metabolic rate of synovial tissue $[19,20]$. Remans P.H. et al [17] indicate that the chronic oxidative stress observed in synovial T lymphocytes from RA patients originates from intracellularly generated free radicals. It is well demonstrated that AOPPs levels were significantly increased in RA patients compared with healthy individuals [21]. To our knowledge, AOPPs' effect on FLSs still remains unknown. Thus we decided to explore the response of FLSs to AOPPs and investigate the potential effect of AOPPs on FLSs. In the present study, we investigated the effect of AOPPs on the production of cytokines in rat FLSs and discussed whether NADPH and NF- $\kappa B$ were involved in the AOPPs actions on the cells.

\section{Materials and Methods}

AOPPS-RSA Preparation and Determination

AOPPs-Rat Serum Albumin (RSA) was prepared according to a described procedure with minor modifications [2, 22]. Briefly, RSA solution (20 mg/ml, St Louis, MO, USA) was exposed to 200mmol/L of HOCL for 30 mins at room temperature and then dialyzed against PBS at $4^{\circ} \mathrm{C}$ for $24 \mathrm{hrs}$ to remove free HOCL. Control incubation was performed in native RSA dissolved in PBS alone. All the preparations were passed through a Detoxi-Gel column (Thermo, Massachusetts,USA) to remove any endotoxin. An amebocyte lysate assay kit (Sigma,USA) was used to determine the level of endotoxin in both AOPPs-RSA and unmodified RSA group and the concentration of endotoxin in them were below $0.025 \mathrm{EU} / \mathrm{ml}$. AOPPs content in the sample was determined as described previously [1]. Briefly, $200 \mu \mathrm{l}$ of sample or chloramine-T was placed in a 96well plate, and then $20 \mu \mathrm{l}$ of acetic acid was added. A microplate reader was used to measure the absorbance at $340 \mathrm{~nm}$ immediately. AOPPs content in the AOPPs-RSA and unmodified RSA were $49.10 \pm 4.19 \mu \mathrm{mol} / \mathrm{g}$ protein and $0.25 \pm 0.72 \mu \mathrm{mol} / \mathrm{g}$ protein respectively.

\section{Fibroblast-like synoviocytes (FLSS) culture and treatment}

FLSs were obtained according to a described procedure with some modifications [23]. Fresh synovial tissues were isolated aseptically from both knee joints of Female Lewis rats (4 weeks old, 150$200 \mathrm{~g}$ ) and washed with phosphate-buffered saline (PBS). After that they were minced and digested in a solution of $0.2 \%$ collagenase in Dulbecco's modified Eagle's medium (DMEM, Gibco, Life Technologies, California, USA) at $37^{\circ} \mathrm{C}$ for $2.5 \mathrm{hrs}$, the tissue were further digested by $0.25 \%$ trypsin for $2 \mathrm{hrs}$ and then the cells were centrifuged at $1000 \mathrm{~g}$ for 5 mins.

FLSs were seeded in, $25 \mathrm{~cm}^{2}$ flat-bottom culture flasks and supplemented with DMEM containing $10 \%$ fetal bovine serum (FBS) (Gibco, Life Technologies, California, USA) and antibiotics (100 IU/ $\mathrm{ml}$ penicillin, $100 \mathrm{IU} / \mathrm{ml}$ streptomycin, Irvine Scientific, Santa Ana USA). The cells were cultured by incubating at $37{ }^{\circ} \mathrm{C}$ in a humidified atmosphere with $5 \% \mathrm{CO}_{2}$. After reaching a subconfluent state, the cells were subcultured after trypsinization with $0.25 \%$ trypsin $/ 0.02 \%$ EDTA. Third to sixth passage cells were used for all the experiments. All animal procedures performed with permission and followed the guidelines laid down by the Animal Use and Care Committee of Southern Medical University.

During most experiments, FLSs were extensively washed with PBS, cultured in DMEM with 0.5\% serum for $12 \mathrm{hrs}$, and then stimulated by adding control medium, various concentrations of AOPPs-RSA $(50,100,200 \mu \mathrm{g} / \mathrm{ml})$ or unmodified RSA $(200 \mu \mathrm{g} / \mathrm{ml})$ in the presence or absence of antioxidant N-acetyl-Lcysteine (NAC), superoxide dismutase (SOD), diphenyleneiodonium (DPI), apocynin and SN50.(Beyotime, China).

NAC is an antioxidant used to scavenge intracellular ROS [24] and SOD, the antioxidant enzymes, prevent accumulation of superoxide by conversing superoxide to hydrogen peroxide [25]. DPI and apocynin are the inhibitors of NADPH oxidase and block the $\mathrm{O}_{2}^{-}$generation which is dependent on the inactivation

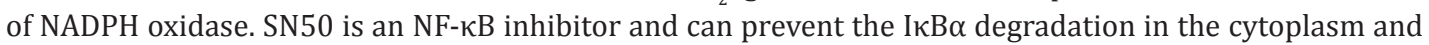
NF- $\kappa B$ p 65 translocation to nucleus, both of which are the essential procedure for the activation of NF- $\kappa B$. 
Table 1. Primer sequences of genes used for real-time PCR analyses

\begin{tabular}{llllc}
\hline Gene name & Primer sequence (5'-3') & Primer sequence(3'-5') & Accession & Product size \\
\hline GAPDH & GGC ACA GTC AAG GCT GAG AAT G & ATG GTG GTG AAG ACG CCA GTA & NM_017008.4 & $165 \mathrm{bp}$ \\
MMP-3 & TCG GTG GCT TCA GTA CCT & CCT CCT CCC AGA CCT TC & NM_133523.2 & $141 \mathrm{bp}$ \\
MMP-13 & CCA GAA CTT CCC AAC CAT & ACC CTC CAT AAT GTC ATA CC & NM_133530.1 & $114 \mathrm{bp}$ \\
TNF- $\alpha$ & CCA CGC TCT TCT GTC TAC TG & GCT ACG GGC TTG TCA CTC & NM_012675.3 & $145 \mathrm{bp}$ \\
IL-1 $\beta$ & TGT TTC CCT CCC TGC CTC T & AAT GCT GCC TCG TGA CCC & NM_031512.2 & $106 \mathrm{bp}$ \\
VEGF & TGC ACC CAC GAC AGA AGG GGA & TCA CCG CCT TGG CTT GTC ACA & NM_001110336.1 & $128 \mathrm{bp}$ \\
\hline
\end{tabular}

Enzyme-linked immunosorbent assay (ELISA)

To investigate whether AOPPs induce cytokines production in FLSs, we analyzed the supernatant of the synovial cells cultured with AOPPs. To be specific, cells were cultured in DMEM with FBS (10\%) and then synchronized for $12 \mathrm{hrs}$ with DMEM/0.5\% FBS. FLSs were stimulated with increasing concentrations of AOPPs $(50,100,200 \mu \mathrm{g} / \mathrm{ml})$ or unmodified RSA $(200 \mu \mathrm{g} / \mathrm{ml})$ or control medium respectively. After that, cell supernatants were collected and centrifuged at $12000 \mathrm{~g}$ for $15 \mathrm{mins}$. Supernatants were stored at $-80^{\circ} \mathrm{C}$ until experimentation. Levels of MMP-3, MMP-13, TNF- $\alpha$, IL-1ßand VEGF in the supernatant were quantified respectively using the MMP-3 ELISA kits (Boster, Wu Han, China), MMP-13 ELISA kit (Cusabio, Wu Han, China ), TNF- $\alpha$ ELISA kit (Boster, Wu Han, China), IL-1ßELISA kit (Boster, Wu Han, China) and VEGF ELISA kit (Cusabio, Wu Han, China) according to the manufacturer's protocol. The OD was measured at $450 \mathrm{~nm}$ by a spectrophotometric plate reader (Molecular Devices, Califomia, USA). All the experiments were performed and tested in triplicate.

Total RNA isolation, reverse transcription (RT) and real-time quantitative polymerase chain reaction(RTPCR)

After stimulation, the total RNA was extracted from the treated and contol FLSs using the TRI Reagent (Takara Biotechnology, Dalian, China) according to the manufacturer's protocol and quantified by a Nanodrop1000 spectrophotometer (Thermo Scientific, Waltham, USA). $1 \mu \mathrm{g}$ of total RNA sample with a 260/280 ratio > 2.0 were used for reverse transcription (RT) using PrimeScript® RT reagent Kit With gDNA Eraser (Takara Biotechnology, Dalian, China) according to the manufacturer's protocol. Sequences for the primers used are given in Table 1. Each specific primer was optimized for concentrations and then the resulting cDNA was PCR amplified using a SYBR® Premix Ex TaqTM II kit (Takara Biotechnology, Dalian, China) according to the manufacturer's instruction. Real-time PCR reactions were carried out on Applied Biosystems 7500 Real-Time PCR System (ABI, Carlsbad, California, USA) with 40 cycles of denaturing at $95^{\circ} \mathrm{C}$ for $30 \mathrm{sec}$, annealing at $95^{\circ} \mathrm{C}$ for $5 \mathrm{sec}$ and extending at $60^{\circ} \mathrm{C}$ for $34 \mathrm{sec}$. After normalizing to the "housekeeping genes" glyceraldehyde-3-phosphate dehydrogenase (GAPDH), the gene expression change was presented as relative expression (fold change from control), and was calculated as previously described using the $2^{-\Delta \Delta C t}$ method [26].

\section{Determination of intracellular ROS generation}

The level of intracellular ROS was assessed by fluorescence microplate reader with the probe 2',7'-dichlorofluorescein diacetate (DCFH-DA), which oxidizes to fluorescent dichlorofluorescein (DCF) in the presence of ROS, as described previously [27]. Briefly, FLSs were suspended in DMEM at a given concentration of $10^{8} / \mathrm{L}$ and $150 \mu \mathrm{L}$ of cells suspension was added to the 96-well plates. Each sample was incubated in $10 \mu \mathrm{M}$ DCFH-DA for 30 mins in darkness followed by AOPPs treatment as described above. Fluorescence intensity was measured on a SpectraMax M5 system (Molecular Devices, Califomia, USA). The excitation and emission wavelength were $488 \mathrm{~nm}$ and $525 \mathrm{~nm}$ respectively. All the obtained data were normalized with the control values.

Immunoprecipitation and immunoblotting analysis

Immunoprecipitation and immunoblotting were peformed respectively to analyze the phosphorylation of $\mathrm{p} 47^{\text {phox }}$ and interaction of $\mathrm{p} 47^{\text {phox }}$ with $\mathrm{p} 22^{\text {phox }}$ or gp $91^{\text {phox }}$ as described previously [28]. Briefly, the cell lysates were incubated with anti-p4 $7^{\text {phox }}$, anti-p22 $2^{\text {phox }}$ or anti-gp91 $1^{\text {phox }}$ antibodies (all purchased from Abcam, 


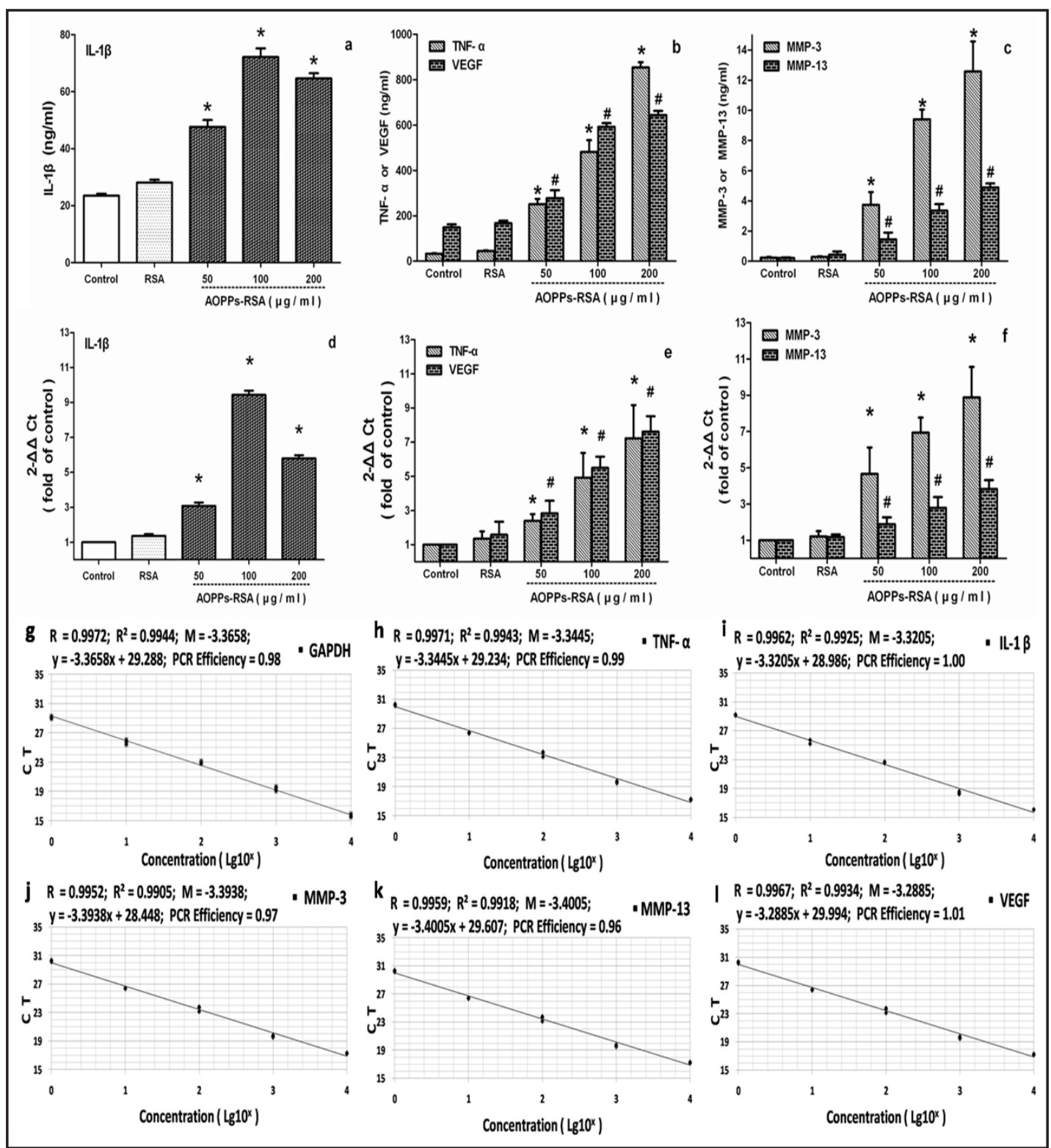

Fig. 1. Advanced oxidation protein products (AOPPs) treatment increased expression of interleukin-1 (IL$1 \beta$ ), tumor necrosis factor- $\alpha$ (TNF- $\alpha$ ), matrix metalloproteinases-3 (MMP-3), matrix metalloproteinases-13 (MMP-13) and vascular endothelial growth factor (VEGF) in both protein and mRNA level. Rat fibroblastlike synoviocytes (FLSs) were incubated with control medium, normal rat serum albumin (RSA) or indicated different concentration of AOPPs for 24 hours. Release of these cytokines into culture supernatants were measured by enzyme-linked immunosorbent assay (ELISA) ( $a, b$ and c) and the expression of mRNA was quantitated by Real-time RT-PCR ( $d$, e and f). The primer efficiencies of the above test index were also shown in the figure $(\mathrm{g}-\mathrm{l})$. Data were presented as mean $\pm \mathrm{SD}$ and experiments were performed in triplicate under each condition. ${ }^{*} \mathrm{P}<0.01$ vs control.

Cambridge, UK, dilution 1:5000) overnight at $4^{\circ} \mathrm{C}$, respectively. After that $30 \mu$ l protein A/G-beads (Santa Cruz Biotechnology) were added into the antigen-antibody complex at $4^{\circ} \mathrm{C}$ for $30 \mathrm{mins}$. After washing three times with lysis buffer, the immunocomplexes were resolved on SDS-PAGE and then transferred to PVDF membranes. The membranes were then incubated with a HRP-conjugated goat anti-phosphoserine $\mathrm{p} 47^{\text {phox }}$ antibody (Upstate-Cell Signaling Solutions, Temecula, CA, dilution 1:2000) to analyze the phosphorylation of $\mathrm{p} 47^{\text {phox }}$. In order to determine the interaction of $\mathrm{p} 47^{\text {phox }}$ with $\mathrm{p} 22^{\text {phox }}$ or gp $91^{\text {phox }}$ the rabbit anti-rat $\mathrm{p} 47^{\text {phox }}$ 


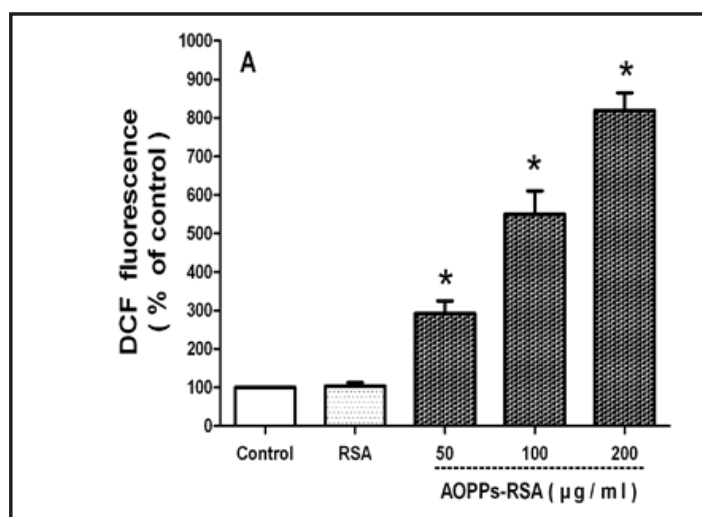

Fig. 2. AOPPs challenge increased reactive oxygen species (ROS) generation in FLSs. FLSs cultured as control cells, RSA group or indicated concentration of AOPPs as AOPPs group for 1 hour or $200 \mu \mathrm{g} / \mathrm{ml}$ of AOPPs for indicated time. ROS generation was evaluated by fluorescence microplate system with the probe 2',7'-dichlorofluorescein diacetate ( DCFHDA). AOPPs triggered ROS overproduction in both at varing concentration- (A) and time- dependent manner (B). To verify the source of ROS generation, the experiments were repeated in the presence of $\mathrm{N}$ acetyl-L-cysteine (NAC) (20umol/L,2h), superoxide dismutase (SOD) (15mmol/L,2h), diphenyleneiodonium (DPI) (10umol/L,2h) and apocynin (500mol/ $\mathrm{mL}, 2 \mathrm{~h}$ ) (C). Mean values + standard deviation (SD) of three independent experiments are shown. ${ }^{*} \mathrm{P}<0.01$ vs control group, $\# \mathrm{P}<0.01$ vs AOPPs group.
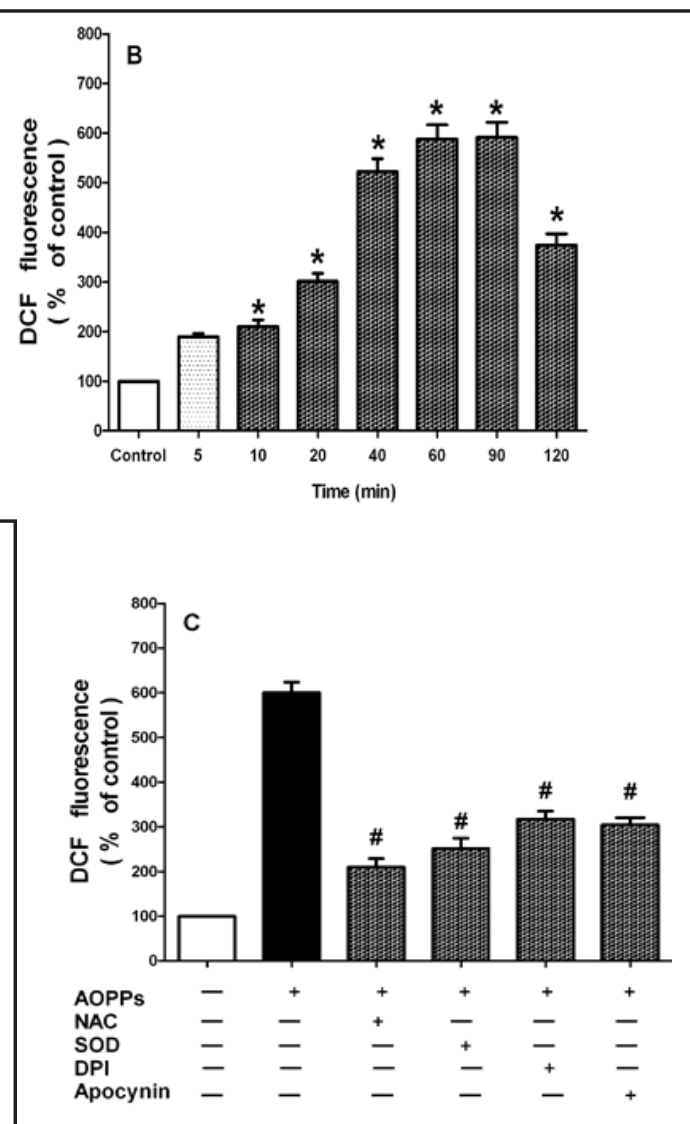

antibody (Stressgen Bioreagents Victoria, BC, Canada, dilution 1:5000) and the HRP-conjugated goat anti-rabbit IgG (DakoCytomation, dilution 1:5000) were used as the primary antibody and the secondary antibody respectively.

To determine total $\mathrm{p} 47^{\text {phox }}, \mathrm{p} 22^{\text {phox }}$ or gp91 $91^{\text {phox }}$, the membranes were washed with an elute buffer, reacted with anti-p47 $7^{\text {phox }}$ monoclonal antibody, anti-p22 $2^{\text {phox }}$ or anti-gp91 ${ }^{\text {phox }}$ polyclonal antibodies (all purchased from BD Biosciences Pharmingen, San Diego, CA, dilution 1:2000) respectively and then detected by the HRP-conjugated anti- IgG antibody (DakoCytomation, dilution 1:5000).

\section{Western blot analysis}

Western blotting was performed to detect the specificity of antigen-antibody interaction using total cellular proteins and the nuclear proteins, extracted from FLSs according to manufacture's instruction of nuclear and cytoplasmic extraction reagents kit (Beyotime, Beijing, China). The protein quantification was determined by BCA Protein Assay kit and then heated in sodium dodecyl sulfate-polyacrylamide gels electrophoresis (SDS-PAGE) protein loading buffer at $95^{\circ} \mathrm{C}$ for $10 \mathrm{mins}$.

Proteins $(35 \mu \mathrm{g}$ ) were loaded per lane and separated by 10\% SDS-PAGE and electrotransferred to PVDF membranes by a semi-dry transfer. Then the PVDF membranes was blocked in 5\% nonfat milk in TBSTween for $1 \mathrm{hr}$ at room temperature and incubated overnight at $4{ }^{\circ} \mathrm{C}$ with the primary antibodies anti-NF- $\mathrm{KB}$

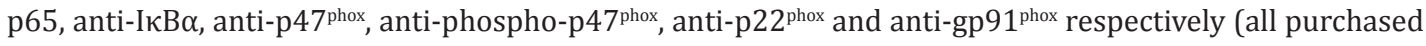
from BD Biosciences Pharmingen, San Diego, CA, dilution 1:2000). Later the membranes were washed three times for 10 mins each in TBST and incubated for $1 \mathrm{hr}$ at room temperature with an appropriate HRP-linked secondary antibodies (Upstate-Cell Signaling Solutions, Temecula, CA, dilution 1:2000). The relative levels of protein were determined by densitometry using Total Lab 2.0 software. 


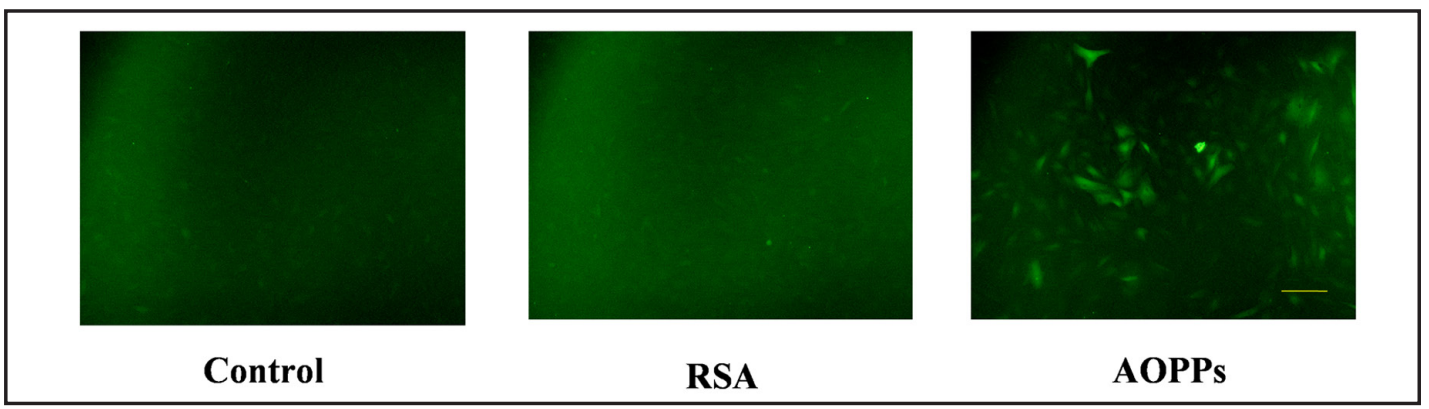

Fig. 3. Representative photographs of FLSs treated with or without AOPPs. FLSs were cultured with control medium, RSA or AOPPs $(200 \mu \mathrm{g} / \mathrm{ml})$ for 90 mins. A fluorescent microscopy was used to visualize ROS generation in FLSs with DCFH-DA. (Scale bar $=100 \mu \mathrm{m}$ ).

\section{Statistical analysis}

All the experiments were performed in triplicate. Results were expressed as mean \pm standard deviation.

Statistical differences between means for different groups were compared using one-way ANOVA (analysis of variance). Multiple comparisons were performed using the LSD method or Dunnett's C method. Comparing several treatments with control group were was evaluated by the Dunnett's T3 procedure. Statistical analyses were conducted with SPSS 13.0 software.

\section{Results}

Effect of AOPPs stimulation on the expression of IL-1 $\beta$, TNF- $\alpha, M M P-3, M M P-13$ and VEGF. Initially, we tested whether AOPPs can induce FLSs to release cytokines. As shown in Fig. 1 a-c, secretion of cytokine IL-1 $\beta$, TNF- $\alpha$, MMP-3, MMP-13 and VEGF by FLSs in AOPPs group were in a concentration-dependent manners compared with low levels detected in the conntrol cells and unmodified RSA group (Fig.1 b and c). However, it is seen that the expression of IL-1 $1 \beta$ in $200 \mu \mathrm{g} / \mathrm{ml}$ AOPPs group was lower than that in $100 \mu \mathrm{g} / \mathrm{ml}$ AOPPs group but still at a signaficantly higher levels than control cells and RSA group (Fig. 1a).

Real-time RT-PCR is used to quantify the effect of AOPPs at various concentrations on the expression of IL-1 $\beta$, TNF- $\alpha$, MMP-3, MMP-13 and VEGF in mRNA (Fig. $1 \mathrm{~d}$-f). Compared with the control cells and unmodified RSA group, the mRNA levels were significantly increased when FLSs were cultured with AOPPs. And no significant difference was found in the messenger RNA expression between unmodified RSA group and control cells. When the above data is evaluated, it indicates that FLSs can be stimulated by AOPPs to secrete cytokines at both protein and gene level, which may be involved in the pathological progression of RA.

AOPPs induce ROS generation in FLSS

In order to study the ROS generation in FLSs, we challenged AOPPs group in FLSs and noticed a siginificant increase of ROS level (3- to 8-fold) in AOPPs group compared to both unmodified RSA cells and control cells (Fig.2 A). When FLSs were incubated with AOPPs at different concentration within 90 mins it showed a time-dependent increase in ROS generation (Fig. 2B). Furthermore, the ROS generation in FLSs cultured with AOPPs was observed under a fluorescence microscopy with DCFH-DA (Fig. 3).

We then measured the contribution of SOD, NAC, DPI and apocynin respectively to determine the source of ROS and it was found that SOD, NAC, DPI and apocynin decreased the OD value of DCF in FLSs significantly (Fig. 2C). These data indicate that AOPPs induced ROS over production can be significantly reduced by direct action of SOD and NAC on ROS, where as DPI and apoctnin, the inhibitors of NADPH oxidase, decrease the levels of elevated ROS via NADPH. 


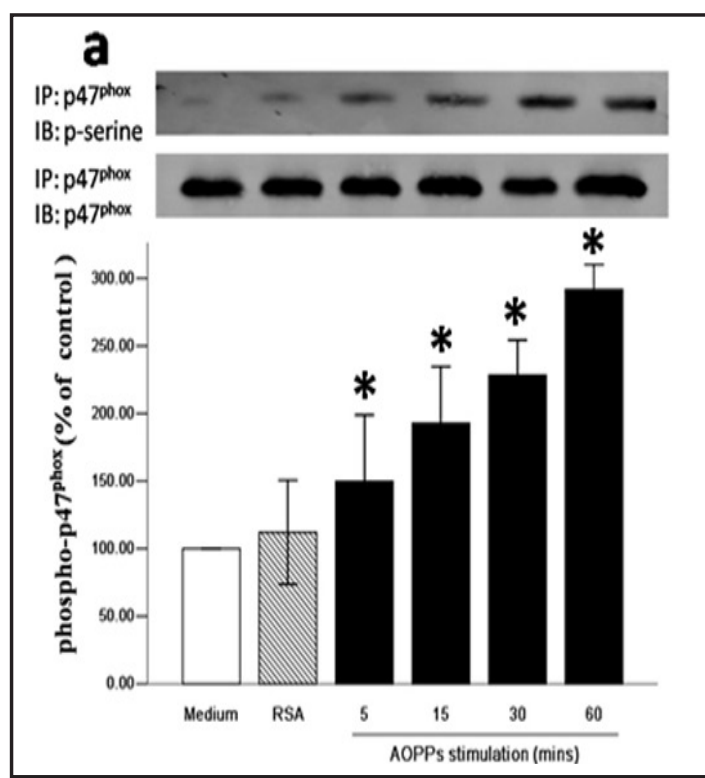

Fig. 4. Nicotinamide adenine dinucleotide phosphate (NADPH) oxidase are actived by AOPPs in cultured FLSs. (a) FLSs were treated with $200 \mu \mathrm{g} /$ $\mathrm{ml}$ of AOPPs-RSA or native RSA for an indicated time. Phosphorylation of $\mathrm{p} 47^{\text {phox }}$ was assayed by immunoprecipitation (IP) using a $\mathrm{p} 47^{\text {phox }}$ antibody and detected by immunoblotting (IB) using a pan-p47 $7^{\text {phox }}$ and a phosphoserine-p47 phox as the primary antibodies. (b) AOPP-induced interaction of $\mathrm{p} 47^{\text {phox }}$ with $\mathrm{p} 22^{\text {phox }}$ and gp $91^{\text {phox }}$. FLSs were treated as described above. IP was performed using $\mathrm{p} 22^{\text {phox }}$ and $\mathrm{gp} 91^{\text {phox }}$, and IB was conducted using an $\mathrm{p} 47^{\text {phox }}$. (c) Expression of NADPH oxidase subunits in cultured FLSs. FLSs were incubated with or without AOPPs for 1-24 h. Protein expression of NADPH oxidase was determined by western blot using antibodies against NADPH oxidase subunits. Data were presented as mean \pm SD from triplicate. ${ }^{*} \mathrm{P}<0.05$ vs medium alone.
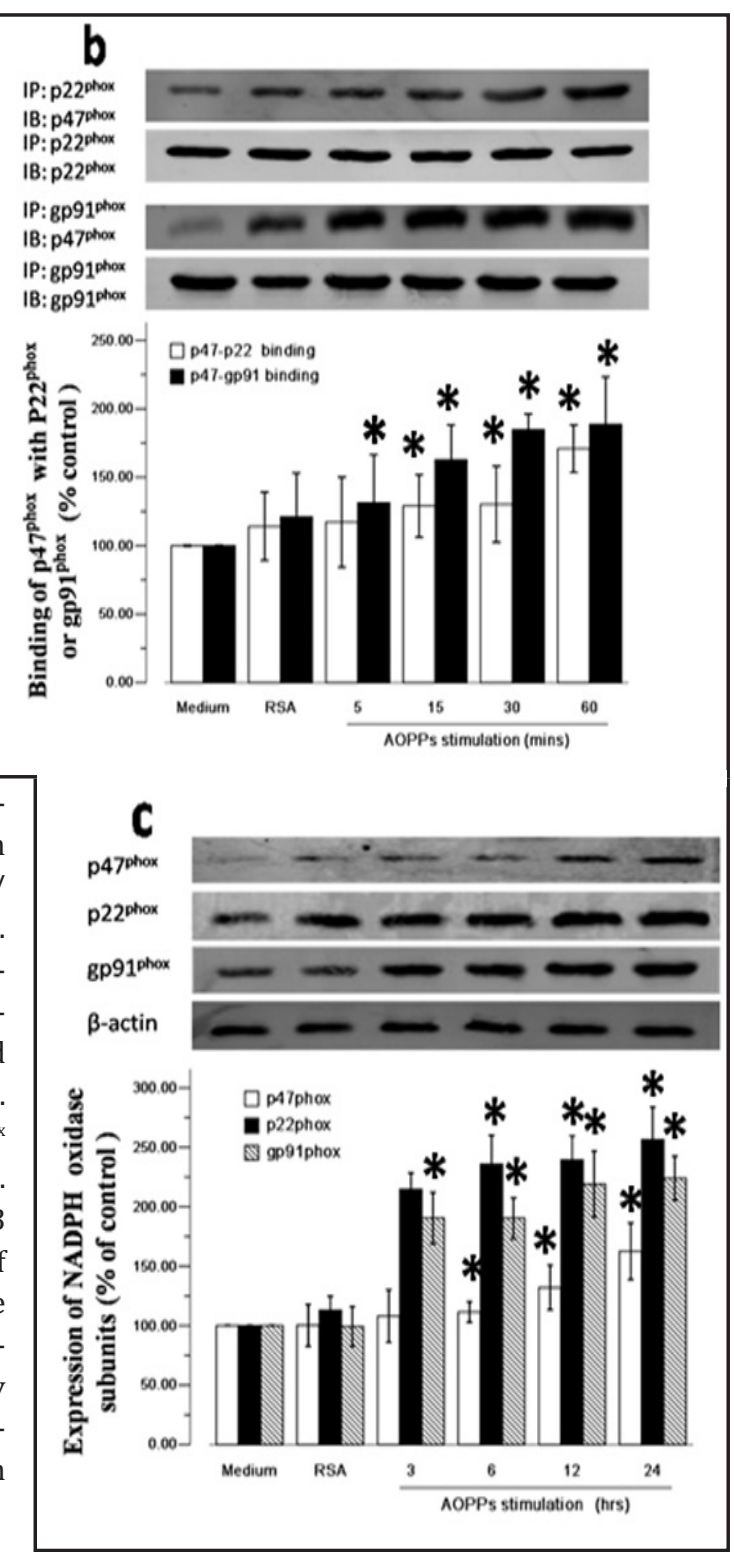

AOPPs challenge activated NADPH oxidase in FLSS

To investigate whether AOPPs treatment activate NADPH oxidase, initially we measured the phosphorylation of $\mathrm{p} 47^{\text {phox }}$, a subunit of NADPH oxidase located in the cytoplasm of the FLSs. AOPPs group showed rapid phosphorylation of $\mathrm{p} 47^{\text {phox }}$ at 5 mins, and peaked at 60 mins, where as control group and RSA group had no siginificant effect (Fig. 4a). Translocation of $\mathrm{p} 47^{\text {phox }}$ to the cell membrane plays a key role in NADPH oxidase activation [29]. In order to examine the interaction of $\mathrm{p} 47^{\text {phox }}$ with the membrane subunits, we immunoprecipitated $\mathrm{p} 22^{\text {phox }}$ and gp91 ${ }^{\text {phox }}$ with the specific antibodies and then probed for the coexistence of $\mathrm{p} 47^{\text {phox }}$ in the cells. The amount of $\mathrm{p} 47^{\text {phox }}$ - gp $91^{\text {phox }}$ complex rapidly increased in AOPPs group at 5 mins and p $47^{\text {phox }}-\mathrm{p} 22^{\text {phox }}$ complex appeared later than p47 ${ }^{\text {phox }}$ gp $91^{\text {phox }}$ complex at 15 mins (Fig. 4b). Likewise, to determine sustained activity of NADPH oxidase we examined the protein levels of its subunits in FLSs treated with or without AOPPs. AOPPs group showed significant upregulated expression of $\mathrm{p} 47^{\text {phox }}, \mathrm{p} 22^{\text {phox }}$ and gp $91^{\text {phox }}$ compared with control cells after 6 hrs. Only the expression of gp $91^{\text {phox }}$ was increased after $3 \mathrm{hrs}$ in AOPPs group (Fig. 4c). 

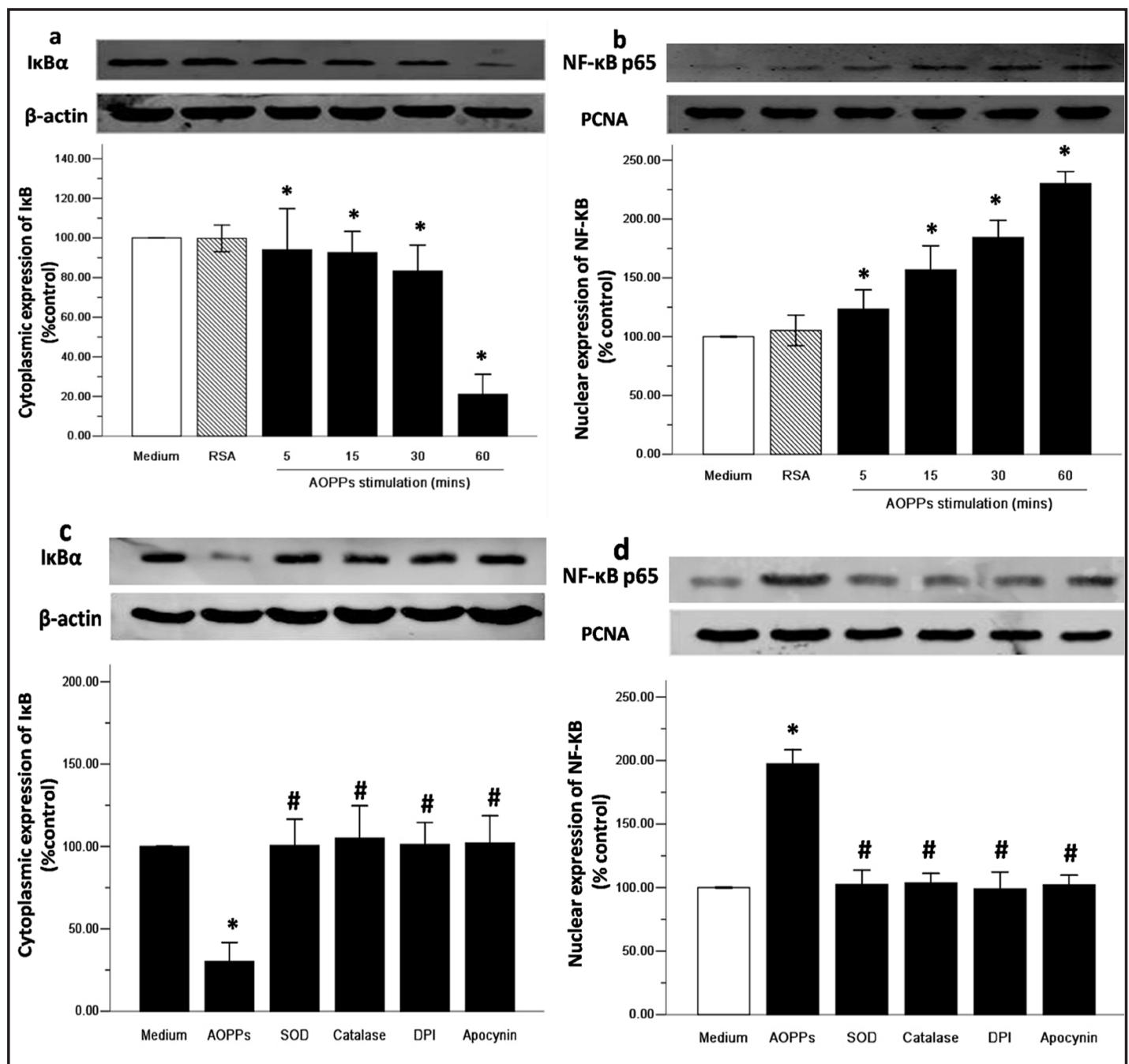

Fig. 5. Effect of AOPPs on the nuclear factor kappa B (NF- $\kappa B)$ activation in FLSs. FLSs were treated with $200 \mu \mathrm{g} / \mathrm{ml}$ of AOPPs-RSA or native RSA for indicated time. Decreased expression of I $\mathrm{B} \alpha$ was observed in cytoplasm of AOPPs challenged FLSs (a) and increased expression of NF- $\kappa$ B p65 was observed in nucleus of the cells (b). FLSs pre-treated by NAC(20umol/L), SOD(15mmol/L), DPI(10umol/L) and apocynin(500mol/

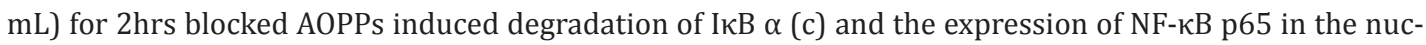
lear. $\beta$-actin and PCNA were used as loading control in cytoplasm and nuclear respectively. All data points were normalized as a percentage of the corresponding control cells. Data were presented as mean \pm SD from triplicate. ${ }^{*} \mathrm{P}<0.05$ vs medium alone. \#P $<0.05$ vs AOPPs group.

Effects of AOPPs on I $\kappa$ B $\alpha$ degradation and nuclear translocation of NF- $\kappa B$ in FLSS

In order to explore the potential molecular mechanism underlying the AOPPs actions on FLSs, western blot was performed to examine if AOPPs triggers NF- $\kappa B$ activation in the cells. As we know two important steps before NF- $\kappa B$ activation are I $\kappa B \alpha$ degradation in cytoplasm

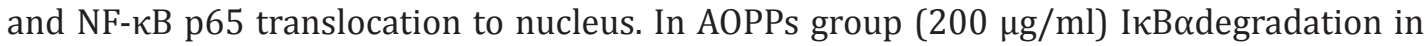

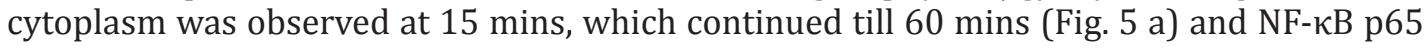
proteins showed an increased level in nucleus from 5 mins till 60 mins. (Fig. 5b). These data suggested that AOPPs can induce the degradation of I $\mathrm{K} \alpha \alpha$, which leads to the nuclear translocation of p65 and at last activate NF- $\mathrm{kB}$ in FLSs.

Evidence had been shown that NF- $\mathrm{BB}$ is a redox-sensitive transcription factor [30] and AOPPs have been considered as a marker of oxidative stress [1]. Accordingly, treating the cells with SOD, catalase, DPI and apocynin was performed to investigate if ROS mediated 


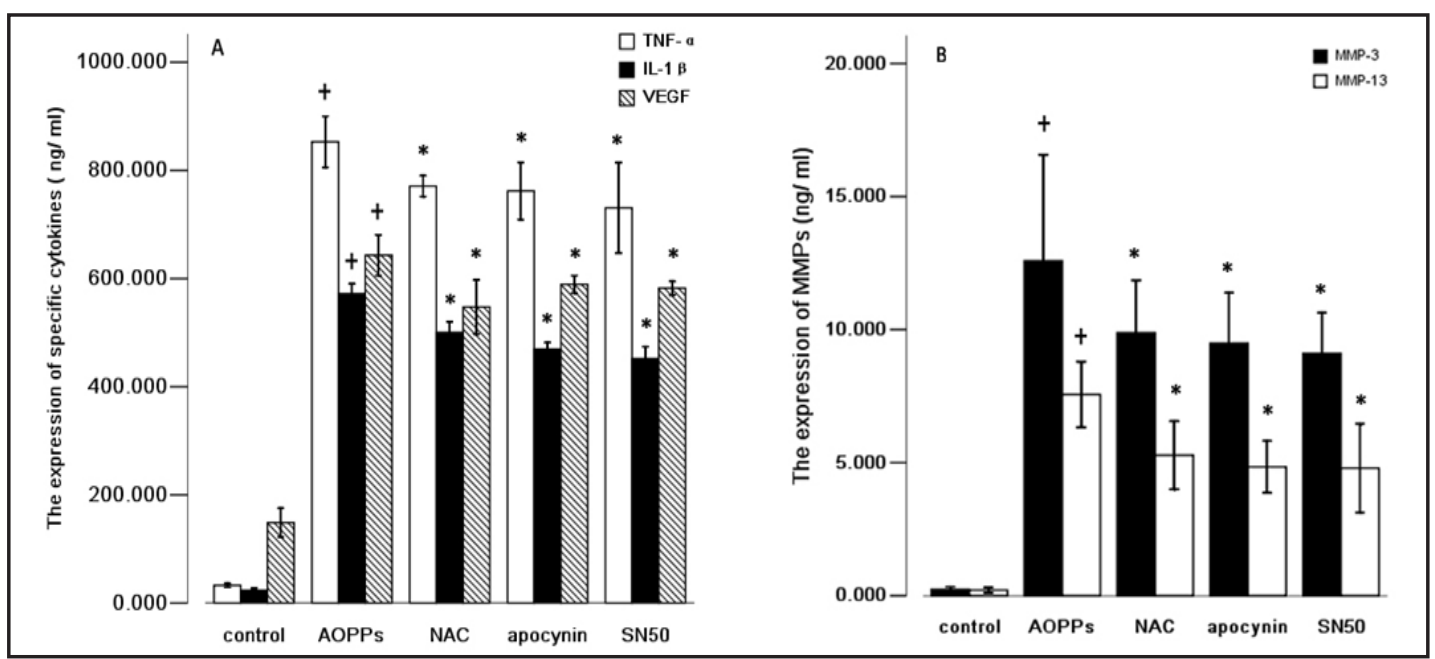

Fig. 6. The inhibitory effects of NAC, apocynin and SN50 on AOPPs-induced cytokines generation. FLSs were cultured with NAC (20umol/L), apocynin $(500 \mathrm{~mol} / \mathrm{ml})$ and SN50 $(100 \mu \mathrm{g} / \mathrm{ml})$ respectively for 2 hour and then added AOPPs $(200 \mu \mathrm{g} / \mathrm{ml})$ and further incubated for another $24 \mathrm{~h}$. Addition of NAC, apocynin and SN50 blocked AOPPs-induced release of IL-1 $\beta$ (A), TNF- $\alpha$ (A), VEGF (A), MMP-3 (B) and MMP-13 (B). The experiments were repeated three times with duplicates for each treatment. Data were presented as mean $\pm \mathrm{SD}$, ${ }^{*} \mathrm{P}<0.05$ vs AOPPs. ${ }^{+} \mathrm{P}<0.05$ vs control group.

AOPPs- challenged could caused NF- $\mathrm{BB}$ activation. As shown in Fig. $5 \mathrm{c}$ and Fig. $5 \mathrm{~d}$, both I $\kappa \mathrm{B} \alpha$ degradation and NF- $\kappa \mathrm{B}$ p 65 translocation to the nucleus were inhibited in the presence of SOD, catalase, DPI and apocynin. All of the above data indicates that ROS generation via NADPH activation plays an important role in AOPPs- induced NF- $\kappa B$ activation.

NAC, apocynin and SN50 counteracted AOPPs-promoted the release of cytokines.

To test the possible participation of NADPH oxidase, ROS production and NF- $\kappa B$ in AOPPs group, we employed their specific inhibitors NAC, apocynin and SN50 respectively. As shown in Fig. 6, NAC, apocynin and SN50 abrogated TNF- $\alpha$, IL-1 $\beta$, MMP-3, MMP-13 and VEGF production induced by AOPPs in FLSs. These data pointed out that NADPH oxidase, ROS production and NF- $\mathrm{KB}$ are involved in the generation of AOPPs-induced above cytokines.

\section{Discussion}

AOPPs have been reported to play a key role in many pathological conditions [4-6] and also takes part in a number of biological activities as a modulated factor [31-33]. Moreover, a study showed that patients with RA have a higher level of AOPPs as compared to the normal individuals [21]. Whether the accumulation of AOPPs in patients with RA could accelerate the disease progression remains unknown. Therefore, FLSs, the main functional cells involved in the pathophysiology of RA [12], were essential to our study, under the treatment of AOPPs.

Evidence shows that TNF- $\alpha$ drives these basic pathophysiological effect in RA [34] and both TNF- $\alpha$ and IL-1 $\beta$ are potent stimulators of synovial tissue in vitro [16]. TNF- $\alpha$ and IL-1 $\beta$ are central to the damaging cascade, which triggers the production of MMPs and ultimately results in irreversible damage to synovium and articular cartilage [35]. In this study, we found that FLSs exposed to AOPPs expressed high levels of TNF- $\alpha$ and IL-1 $\beta$ at both proteins and gene level compared with control cells. Whereas, FLSs cultured with unmodified RSA did not have any significant expression of TNF- $\alpha$ and IL- $1 \beta$. All these data shows that AOPPs, and not RSA, could induce FLSs to release the pro-inflammatory cytokines TNF- $\alpha$ and IL$1 \beta$. Therefore, the high level of AOPPs detected in RA patients may accelerate the disease progression through the release of these two pro-inflammatory cytokines. 
Fig. 7. AOPPs induce the inflammatory response in FLSs by activation of NF- $\mathrm{KB}$ through NADPH oxidase-dependent ROS generation in vitro.

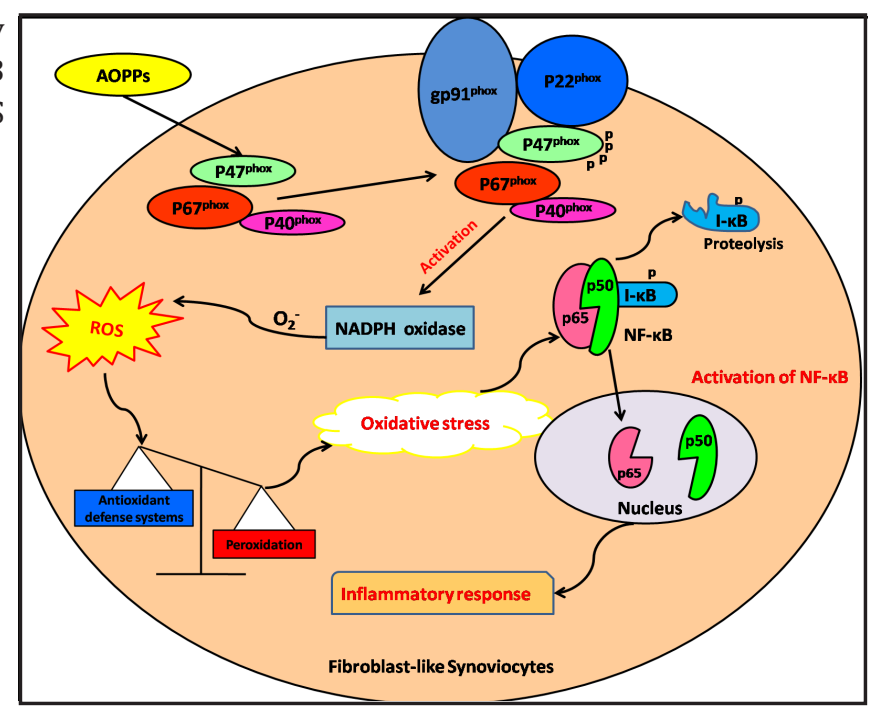

MMP-3 and MMP-13, which degrade the extracellular matrix of cartilage, played a vital role in the occurrence, development and progression of RA. MMP-3, also known as a stromelysin-1, has a broader substrate specificity, with activity against type II, III, IV, IX, $\mathrm{X}$ and XI collagens, proteoglycans, fibronectin and laminin and is the most widely studied members in RA [15]. MMP-13, which preferentially degrades type II collagen and aggrecan was exclusively expressed in $80-90 \%$ patients of RA [36]. To the best of our knowledge, the effect of AOPPs on the MMPs production has not been studied so far. In the current experiment, we could see AOPPs challenge leads to increase of gene and protein expression in both MMP-3 and MMP-13. Likewise, the unmodified RSA group could not show siginificant changes in these enzyme expression compared with the control cells. From these line of evidence, it is very likely that elevated concentration of AOPPs could result in the release of MMPs in FLSs, which could accelerate the disease progression in RA patients by destroying the synovium tissue and articular cartilage of the joints.

VEGF, a prominent angiogenesis marker, is a prognostic factor regarding the destruction of the joints and the elevated plasma levels of VEGF correlate well with the disease activity in RA patients [37]. Pannus, a prominent feature of RA, is an inflammatory synovial tissue where many newly formed vessels are observed. Formation of new blood vessels permits an efficient supply of nutrients and oxygen to the augmented inflammatory cell mass and that would contribute to perpetuation of the joint disease [38]. In order to investigate whether AOPPs were indeed a regulator of VEGF production in RA, we analyzed the content of VEGF in FLSs after incubating with AOPPs for 24h. As shown in Fig. 1E, the level of VEGF was increased with the increased concentration of AOPPs and the same condition was observed in the mRNA level (Fig. 2E). Therefore, from the data presented we could conclude to some extent that AOPPs might act as a pathologic factor in the procession of RA by inducing FLSs to release VEGF.

ROS can be generated by many kinds of cells through normal cellular metabolism. However, excess production of intracellular ROS, by various stimulations, reactions is the main cause of oxidative stress and has been implicated in the pathogenesis of RA [39]. Here in our study, AOPPs treated FLSs shows significant increase in ROS generation, which was confirmed by addition of NAC and SOD (ROS scavenging) which resulted in decrease of DCF fluorescence. Samir G [40] pointed out that ROS could induce pro-inflammatory cytokines, such as TNF- $\alpha$ and IL-1 $\beta$, followed by an inflammatory response, which was demonstrated in our experiment. All in all, these findings indicated that ROS plays a siginificant role in downstream signaling of AOPPs stimulation.

But how AOPPs challenge induced the generation of ROS in FLSs remained to be investigated. Many kinds of subcellular structure including mitochondria, NADPH oxidases, 
arachidonic acid pathway enzymes lipoxygenase and cyclooxygenase, cytochrome p450s, xanthine oxidase, NO synthase, peroxidases, and other hemoproteins are the sources of ROS generation in mammalian cells [41] but NADPH is one of the most primary source of ROS in diverse cell types $[42,43]$. Under the conditions of our experiment, we found that AOPPs triggers ROS generation in FLSs through activation of the NADPH oxidase since apocynin and DPI, are the inhibitors of NADPH and could block the overproduction of ROS. This results are exciting and in the next step we measured the performance of the NADPH oxidase subunits. Firstly, by the ability of AOPPs to induce rapid phosphorylation of cytoplasmic subunit $\mathrm{p} 47^{\text {phox }}$ in FLSs and secondly by the increased binding of $\mathrm{p} 47^{\text {phox }}$ with the membrane subunit p22 $2^{\text {phox }}$ or gp91 ${ }^{\text {phox }}$, a crucial process which acts as a switch in activation of NADPH oxidase. Unmodified RSA group had no effect. The continuous expression of NADPH oxidase subunits is necessary for its persistent activation [44]. After incubating with AOPPs for 3-24h, the expression of oxidase subunits $\mathrm{p} 47^{\text {phox }}, \mathrm{p} 22^{\text {phox }}$ and gp91 $91^{\text {phox }}$ were all upregulated. Likewise this phenomenon was not seen either in the control cells or RSA group. Collectively, these data strongly suggests that AOPPs, considered as an important marker of oxidative stress, could act as a key mediator for activation of NADPH oxidase in FLSs.

The NF- $\kappa B$ family of transcriptional activators are involved in regulation of cell proliferation, differentiation, apoptosis, immunity, inflammation and cytokine expression induced by various kinds of stimuli [45]. In the inactive state, NF- $\kappa B$ is largely located in the cytoplasm by forming a complex with IкB proteins. As soon as stimulated by extracellular

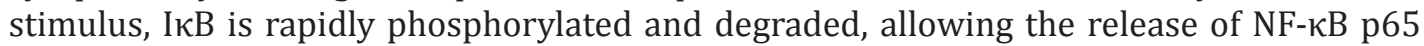
and its subsequent translocation into the nucleus, in which it activates the transcription of genes that contain an NF- $\kappa B$ binding site [46]. In our study, I $\kappa B$ degradation and NF- $\kappa B$ p65 activation were both observed in FLSs treated with AOPPs from 5 to 60 mins. Since AOPPs attenuated the expression of I $\kappa$ B in cytoplasm and meanwhile increased the content of NF$\kappa \mathrm{B}$ p65 in nucleus, we had formed a strong point to believe that AOPPs may be involved in the activation of NF- $\kappa \mathrm{B}$ in FLSs._Additionally, when the cells were pre-treated with ROS scavengers (SOD and catalase) or NADPH oxidase inhibitors (DPI and apocynin), both IкB degradation and NF- $\mathrm{KB}$ p65 activation were blocked. These findings further points out the increased activity of NF- $\mathrm{KB}$ under AOPPs treatment might well be related to NADPH oxidasedependent ROS generation.

\section{Conclusions}

In summary, the present study indicates that AOPPs induce the inflammatory response in FLSs by activation of NF- $\kappa B$ through NADPH oxidase-dependent ROS generation in vitro (Fig. 7). These results give us a new insight to explore the targets for intervention in treating immunological diseases such as RA.

\section{Conflict of Interest}

The authors declare that they have no competing interests.

\section{Acknowledgements}

This work was supported in part by the National Natural Science Foundation of China (No.81272042 and No.81000785) and by the Natural Science Foundation of Guangdong Province (No.S2012010008875 and No.S2012040006830). 
Zheng et al.: AOPPs Induce Inflammatory Response in FLS

\section{References}

1 Witko-Sarsat V, Friedlander M, Nguyen KT, Capeillere-Blandin C, Nguyen AT, Canteloup S, Dayer JM, Jungers P, Drueke T, Descamps-Latscha B: Advanced oxidation protein products as novel mediators of inflammation and monocyte activation in chronic renal failure. J Immunol 1998;161:2524-2532.

- Witko-Sarsat V, Friedlander M, Capeillere-Blandin C, Nguyen-Khoa T, Nguyen AT, Zingraff J, Jungers P, Descamps-Latscha B: Advanced oxidation protein products as a novel marker of oxidative stress in uremia. Kidney Int 1996;49:1304-1313.

3 Martin-Gallan P, Carrascosa A, Gussinye M, Dominguez C: Biomarkers of diabetes-associated oxidative stress and antioxidant status in young diabetic patients with or without subclinical complications. Free Radic Biol Med 2003;34:1563-1574.

4 Atabek ME, Keskin M, Yazici C, Kendirci M, Hatipoglu N, Koklu E, Kurtoglu S: Protein oxidation in obesity and insulin resistance. Eur J Pediatr 2006;165:753-756.

-5 Krzystek-Korpacka M, Neubauer K, Berdowska I, Boehm D, Zielinski B, Petryszyn P, Terlecki G, Paradowski L, Gamian A: Enhanced formation of advanced oxidation protein products in ibd. Inflamm Bowel Dis 2008;14:794-802.

6 Kocak H, Oner-Iyidogan Y, Gurdol F, Oner P, Suzme R, Esin D, Issever H: Advanced oxidation protein products in obese women: its relation to insulin resistance and resistin. Clin Exp Med 2007;7:173-178. Zhou QG, Zhou M, Lou AJ, Xie D, Hou FF: Advanced oxidation protein products induce inflammatory response and insulin resistance in cultured adipocytes via induction of endoplasmic reticulum stress. Cell Physiol Biochem 2010;26:775-786.

8 Liu SX, Hou FF, Guo ZJ, Nagai R, Zhang WR, Liu ZQ, Zhou ZM, Zhou M, Xie D, Wang GB, Zhang X: Advanced oxidation protein products accelerate atherosclerosis through promoting oxidative stress and inflammation. Arterioscler Thromb Vasc Biol 2006;26:1156-1162.

9 Chen S, Liu L, Sun X, Liu Y, Song T: Captopril restores endothelium-dependent relaxation induced by advanced oxidation protein products in rat aorta. J Cardiovasc Pharmacol 2005;46:803-809.

10 Zhong ZM, Bai L, Chen JT: Advanced oxidation protein products inhibit proliferation and differentiation of rat osteoblast-like cells via nf-kappab pathway. Cell Physiol Biochem 2009;24:105-114.

11 Goronzy JJ, Weyand CM: T-cell regulation in rheumatoid arthritis. Curr Opin Rheumatol 2004;16:212-217.

12 Muller-Ladner U, Gay RE, Gay S: Activation of synoviocytes. Curr Opin Rheumatol 2000;12:186-194.

13 Pope RM: Apoptosis as a therapeutic tool in rheumatoid arthritis. Nat Rev Immunol 2002;2:527-535.

14 Bodolay E, Koch AE, Kim J, Szegedi G, Szekanecz Z: Angiogenesis and chemokines in rheumatoid arthritis and other systemic inflammatory rheumatic diseases. J Cell Mol Med 2002;6:357-376.

15 Chen Y, Nixon NB, Dawes PT, Mattey DL: Influence of variations across the mmp-1 and -3 genes on the serum levels of mmp-1 and -3 and disease activity in rheumatoid arthritis. Genes Immun 2012;13:29-37. Lee DM, Weinblatt ME: Rheumatoid arthritis. Lancet 2001;358:903-911. Remans PH, van Oosterhout M, Smeets TJ, Sanders M, Frederiks WM, Reedquist KA, Tak PP, Breedveld FC, van Laar JM: Intracellular free radical production in synovial t lymphocytes from patients with rheumatoid arthritis. Arthritis Rheum 2005;52:2003-2009.

18 Deguchi H, Yasukawa K, Yamasaki T, Mito F, Kinoshita Y, Naganuma T, Sato S, Yamato M, Ichikawa K, Sakai K, Utsumi H, Yamada K: Nitroxides prevent exacerbation of indomethacin-induced gastric damage in adjuvant arthritis rats. Free Radic Biol Med 2011;51:1799-1805.

19 Tak PP, Zvaifler NJ, Green DR, Firestein GS: Rheumatoid arthritis and p53: how oxidative stress might alter the course of inflammatory diseases. Immunol Today 2000;21:78-82.

20 Mapp PI, Grootveld MC, Blake DR: Hypoxia, oxidative stress and rheumatoid arthritis. Br Med Bull 1995;51:419-436.

-21 Baskol G, Demir H, Baskol M, Kilic E, Ates F, Karakukcu C, Ustdal M: Investigation of protein oxidation and lipid peroxidation in patients with rheumatoid arthritis. Cell Biochem Funct 2006;24:307-311.

-22 Li HY, Hou FF, Zhang X, Chen PY, Liu SX, Feng JX, Liu ZQ, Shan YX, Wang GB, Zhou ZM, Tian JW, Xie D: Advanced oxidation protein products accelerate renal fibrosis in a remnant kidney model. J Am Soc Nephrol 2007;18:528-538.

23 Hinoi E, Ohashi R, Miyata S, Kato Y, Iemata M, Hojo H, Takarada T, Yoneda Y: Excitatory amino acid transporters expressed by synovial fibroblasts in rats with collagen-induced arthritis. Biochem Pharmacol 2005;70:1744-1755.

24 Li JJ, Tang Q, Li Y, Hu BR, Ming ZY, Fu Q Qian JQ Xiang JZ: Role of oxidative stress in the apoptosis of hepatocellular carcinoma induced by combination of arsenic trioxide and ascorbic acid. Acta Pharmacol Sin 2006;27:1078-1084. 


\section{Cellular Physiology Cell Physiol Biochem 2013;32:972-985 and Biochemistry

-25 Keller JN, Kindy MS, Holtsberg FW, St CD, Yen HC, Germeyer A, Steiner SM, Bruce-Keller AJ, Hutchins JB, Mattson MP: Mitochondrial manganese superoxide dismutase prevents neural apoptosis and reduces ischemic brain injury: suppression of peroxynitrite production, lipid peroxidation, and mitochondrial dysfunction. J Neurosci 1998;18:687-697.

26 Pfaffl MW: A new mathematical model for relative quantification in real-time rt-pcr. Nucleic Acids Res 2001;29:e45.

27 Rosenkranz AR, Schmaldienst S, Stuhlmeier KM, Chen W, Knapp W, Zlabinger GJ: A microplate assay for the detection of oxidative products using 2',7'-dichlorofluorescin-diacetate. J Immunol Methods 1992;156:3945.

28 Li JM, Fan LM, Christie MR, Shah AM: Acute tumor necrosis factor alpha signaling via nadph oxidase in microvascular endothelial cells: role of $\mathrm{p} 47$ phox phosphorylation and binding to traf4. Mol Cell Biol 2005;25:2320-2330.

-29 Vignais PV: The superoxide-generating nadph oxidase: structural aspects and activation mechanism. Cell Mol Life Sci 2002;59:1428-1459.

-30 Sun Y, Oberley LW: Redox regulation of transcriptional activators. Free Radic Biol Med 1996;21:335-348.

- 31 Zhou LL, Hou FF, Wang GB, Yang F, Xie D, Wang YP, Tian JW: Accumulation of advanced oxidation protein products induces podocyte apoptosis and deletion through nadph-dependent mechanisms. Kidney Int 2009;76:1148-1160.

-32 Guo ZJ, Niu HX, Hou FF, Zhang L, Fu N, Nagai R, Lu X, Chen BH, Shan YX, Tian JW, Nagaraj RH, Xie D, Zhang $\mathrm{X}$ : Advanced oxidation protein products activate vascular endothelial cells via a rage-mediated signaling pathway. Antioxid Redox Signal 2008;10:1699-1712.

33 Wei XF, Zhou QG, Hou FF, Liu BY, Liang M: Advanced oxidation protein products induce mesangial cell perturbation through pkc-dependent activation of nadph oxidase. Am J Physiol Renal Physiol 2009;296:F427-F437.

-34 Calmon-Hamaty F, Combe B, Hahne M, Morel J: Lymphotoxin alpha stimulates proliferation and proinflammatory cytokine secretion of rheumatoid arthritis synovial fibroblasts. Cytokine 2011;53:207-214. Messori A, Santarlasci B, Vaiani M: New drugs for rheumatoid arthritis. N Engl J Med 2004;351:937-938.

-36 Konttinen YT, Ainola M, Valleala H, Ma J, Ida H, Mandelin J, Kinne RW, Santavirta S, Sorsa T, Lopez-Otin C, Takagi M: Analysis of 16 different matrix metalloproteinases (mmp-1 to mmp-20) in the synovial membrane: different profiles in trauma and rheumatoid arthritis. Ann Rheum Dis 1999;58:691-697.

37 Kurosaka D, Hirai K, Nishioka M, Miyamoto Y, Yoshida K, Noda K, Ukichi T, Yanagimachi M, Furuya K, Takahashi E, Kingetsu I, Fukuda K, Yamada A: Clinical significance of serum levels of vascular endothelial growth factor, angiopoietin-1, and angiopoietin-2 in patients with rheumatoid arthritis. J Rheumatol 2010;37:1121-1128.

-38 Taylor PC: Vegf and imaging of vessels in rheumatoid arthritis. Arthritis Res 2002;4:S99-S107.

- 39 Alver A, Senturk A, Cakirbay H, Mentese A, Gokmen F, Keha EE, Ucar F: Carbonic anhydrase ii autoantibody and oxidative stress in rheumatoid arthritis. Clin Biochem 2011;44:1385-1389.

-40 Sukkar SG, Rossi E: Oxidative stress and nutritional prevention in autoimmune rheumatic diseases. Autoimmun Rev 2004;3:199-206.

41 Cai H, Harrison DG: Endothelial dysfunction in cardiovascular diseases: the role of oxidant stress. Circ Res 2000;87:840-844.

42 Gorlach A, Brandes RP, Nguyen K, Amidi M, Dehghani F, Busse R: A gp91phox containing nadph oxidase selectively expressed in endothelial cells is a major source of oxygen radical generation in the arterial wall. Circ Res 2000;87:26-32.

43 Seno T, Inoue N, Gao D, Okuda M, Sumi Y, Matsui K, Yamada S, Hirata KI, Kawashima S, Tawa R, ImajohOhmi S, Sakurai H, Yokoyama M: Involvement of nadh/nadph oxidase in human platelet ros production. Thromb Res 2001;103:399-409.

44 Inoguchi T, Sonta T, Tsubouchi H, Etoh T, Kakimoto M, Sonoda N, Sato N, Sekiguchi N, Kobayashi K, Sumimoto H, Utsumi H, Nawata H: Protein kinase c-dependent increase in reactive oxygen species (ros) production in vascular tissues of diabetes: role of vascular nad(p)h oxidase. J Am Soc Nephrol 2003;14:S227-S232.

45 Pahl HL: Activators and target genes of rel/nf-kappab transcription factors. Oncogene 1999;18:6853-6866.

46 Gloire G, Legrand-Poels S, Piette J: Nf-kappab activation by reactive oxygen species: fifteen years later. Biochem Pharmacol 2006;72:1493-1505. 